2001

\title{
Magnesium Incorporation In Gan Grown By Molecular-Beam Epitaxy
}
A. J.Ptak
T. H. Myers
L. T. Romano
C. G. Van de Walle
J. E. Northrup

Follow this and additional works at: https://researchrepository.wvu.edu/faculty_publications

\section{Digital Commons Citation}

Ptak, A. J.; Myers, T. H.; Romano, L. T.; Van de Walle, C. G.; and Northrup, J. E., "Magnesium Incorporation In Gan Grown By Molecular-Beam Epitaxy" (2001). Faculty Scholarship. 586.

https://researchrepository.wvu.edu/faculty_publications/586 


\title{
Magnesium incorporation in GaN grown by rf-plasma-assisted molecular-beam epitaxy
}

\author{
A. J. Ptak and T. H. Myers ${ }^{\text {a) }}$ \\ Physics Dept., West Virginia University, Morgantown, WV 26506 \\ L. T. Romano, C. G. Van de Walle, and J. E. Northrup \\ Xerox Palo Alto Research Center, Palo Alto, CA 94304
}

\begin{abstract}
A pronounced dependence of $\mathrm{Mg}$ incorporation on surface polarity was observed in a series of Mg step-doped epitaxial GaN layers grown by rf-plasma-assisted molecularbeam epitaxy. Incorporation was studied for both (0001), or Ga-polarity and (000-1), or $\mathrm{N}$-polarity, orientations. Up to a factor of 30 times more $\mathrm{Mg}$ was incorporated on the $\mathrm{Ga}-$ polarity under certain conditions, as determined by secondary ion mass spectrometry. Measurements indicate surface accumulation of $\mathrm{Mg}$ occurs during growth, with stable accumulations of close to a monolayer of $\mathrm{Mg}$ on the Ga-polarity surface. The presence of atomic hydrogen during growth significantly increased incorporation of $\mathrm{Mg}$ without also incorporating potentially compensating hydrogen.
\end{abstract}

Keywords: GaN, molecular beam epitaxy, p-type doping, Mg, surface polarity

a)tmyers@wvu.edu

Ptak et al. 1 
The group III- nitride system (GaN, AlN, InN and their solid solutions) is of increasing importance in the development of optoelectronic and electronic semiconductor devices, such as light emitting diodes, lasers and heterojunction bipolar transistors. At present, the only technologically feasible p-type dopant, $\mathrm{Mg}$, exhibits a large thermal activation energy of $\sim 200 \mathrm{meV}^{1}$ which results in the ionization of only a few percent of the acceptor atoms at room temperature. Thus, large concentrations of $\mathrm{Mg}$ are required to achieve the p-type conductivity necessary for many device applications. Further complications occur when $\mathrm{Mg}$ is used as the p-type dopant for metal organic chemical vapor deposition (MOCVD) growth of GaN since the Mg must be activated by either electron irradiation ${ }^{2}$ or thermal annealing, ${ }^{3}$ which dissociates $\mathrm{Mg}-\mathrm{H}$ complexes to electrically activate the $\mathrm{Mg}$. In addition, the high growth temperatures $\left(>1000{ }^{\circ} \mathrm{C}\right)$ and severe "Mg memory" effect in MOCVD growth leads to broad doping profiles making careful junction placement difficult. ${ }^{4}$

Molecular beam epitaxy (MBE) is an alternate growth technique that may ameliorate these problems. For example, high p-type activation in as-grown MBE GaN layers has recently been reported for conditions that also give sharp interfaces. ${ }^{4}$ While there have been several studies of $\mathrm{Mg}$ doping during the MBE growth of GaN, ${ }^{4,5,6,7}$ many effects remain poorly understood. In addition, both (0001), or Ga-polar, and (000-1), or $\mathrm{N}$-polar, GaN can be grown by MBE depending on the nucleation conditions. The different surface polarities can yield vastly different results, with some researchers obtaining p-type conduction with $\mathrm{Mg}$ only for the Ga-polarity. ${ }^{6}$

In this letter, we present the results of our study of $\mathrm{Mg}$-incorporation under $\mathrm{Ga}$ stable growth conditions that indicate there is a significant difference in $\mathrm{Mg}$ - 
incorporation between Ga- and $\mathrm{N}$-polar surfaces. This difference can explain many of the puzzling results obtained for Mg-doping by MBE, particularly when combined with $\mathrm{Mg}$ induced surface polarity inversion. Our results also provide strong evidence that surface segregation of $\mathrm{Mg}$ is occurring during growth. In addition, we report results supporting theoretical predictions ${ }^{8}$ that hydrogen enhances $\mathrm{Mg}$ incorporation in $\mathrm{GaN}$.

The Mg-doped GaN layers were grown by rf plasma-assisted MBE using an EPI Unibulb nitrogen plasma source. Conventional effusion cells were used for Ga and Mg. $\mathrm{N}$-polarity GaN was obtained by nucleating $\mathrm{GaN}$ buffer layers directly on sapphire under heavily Ga-rich conditions, as reported previously. ${ }^{9}$ Incorporation in Ga-polarity GaN was studied by growth on MOCVD GaN templates on (0001) sapphire substrates. The substrates were mounted with Sn to the substrate block that was in contact with the monitoring thermocouple. The doped layers were grown at a rate of $0.25 \mu \mathrm{m} / \mathrm{hr}$, which corresponded to a nitrogen flow rate of $0.85 \mathrm{sccm}$ and rf power of $200 \mathrm{~W}$. The samples were grown under Ga-stable conditions that result in high quality GaN growth. ${ }^{9,10,11} \mathrm{Mg}$ step-doped structures were produced by sequentially opening and closing the Mg shutter. Importantly, the in-situ growth rate was monitored using laser interferometry allowing precise correlation between source shuttering and Mg incorporation profiles. All changes in oven and substrate temperatures occurred with the Mg shutter closed. Atomic hydrogen was produced using a thermal cracker (EPI-AHS, EPI Vacuum Products, Inc). Typically, $2 \times 10^{-6}$ Torr beam equivalent pressure of hydrogen was passed through the source operating at $9.5 \mathrm{~A}$. Secondary ion mass spectrometry (SIMS) determination of $\mathrm{Mg}$ and $\mathrm{H}$ concentrations was performed at Charles Evans and Associates (Redwood, Ca). 
Figure 1 contains the SIMS measurement of the Mg concentration profile for a Ga-polarity Mg step-doped structure. The general features observed in this profile are representative of all the structures investigated. The opening and closing of the $\mathrm{Mg}$ shutter is indicated schematically along the bottom of the figure, with the associated $\mathrm{Mg}$ oven temperature listed. By monitoring the growth rate throughout layer growth and combining with other chemical markers measured in SIMS, the correlation with the shutter is accurate within an uncertainty of $100 \mathrm{~nm}$. The various substrate temperatures investigated are also listed in the appropriate regions. A summary of the results measured for all the $\mathrm{Mg}$ step-doped structures is given in Table I.

Several features are immediately obvious. First, at the lower $\mathrm{Mg}$ oven temperatures and higher substrate temperatures there is no evidence of $\mathrm{Mg}$ incorporation. It does appear that $\mathrm{Mg}$ may start to incorporate for a $\mathrm{Mg}$-oven temperature of $250{ }^{\circ} \mathrm{C}$ and a substrate temperature of $650{ }^{\circ} \mathrm{C}$, but at a gradually increasing rate rather than an abrupt turn-on. $\mathrm{Mg}$ is seen to incorporate at larger $\mathrm{Mg}$ flux, with strong substrate temperature dependence as reported previously. ${ }^{7}$ A key feature is that incorporation is out of phase with the opening and closing of the shutter, with the peak in incorporation occurring either when or after the Mg shutter was closed. This is shown for the most significant cases in Figure 2 for (a) nitrogen polarity and (b) gallium polarity growth. Note that significant amounts of $\mathrm{Mg}$ are incorporated after the $\mathrm{Mg}$ shutter was closed, strongly indicative of surface segregation and accumulation of $\mathrm{Mg}$. Indeed, for the Ga-polar growth shown in Fig. 2(b) the SIMS result indicates that approximately $3.3 \times 10^{14} \mathrm{Mg}$ atoms $/ \mathrm{cm}^{2}$ were incorporated after the shutter was closed, corresponding to between $1 / 4$ and $1 / 2$ monolayer of $\mathrm{Mg}$ on the surface of the growing layer. This is consistent with 
calculations ${ }^{12,13}$ which predict stable surface configurations involving either $1 / 4$ or $3 / 4$ monolayers of $\mathrm{Mg}$ in substitutional sites on the GaN surface. By assuming about a monolayer of $\mathrm{Mg}$ on the surface, the measured concentration would indicate approximately $3 \times 10^{-4}$ of the $\mathrm{Mg}$ incorporates in each monolayer of growth while the remainder segregates to the new surface. This fraction is quite close to the number of surface sites available for capturing $\mathrm{Mg}$ atoms estimated previously through indirect means to be $\sim 5 \times 10^{-4}$ using a surface segregation model for a similar growth conditions. ${ }^{14}$ Other reported evidence for surface accumulation of $\mathrm{Mg}$ for $\mathrm{Mg}$-doped $\mathrm{GaN}$ has been based on Auger spectroscopy of layers after growth ${ }^{15}$ and the observation that $\mathrm{Mg}$ acts as a persistent surfactant for the growth of GaN. ${ }^{16}$ In the latter case, the surfactant effect of $\mathrm{Mg}$ remains for a significant period of time after closing the $\mathrm{Mg}$ shutter, indicating that $\mathrm{Mg}$ remains on the surface in the absence of a $\mathrm{Mg}$ flux.

Of particular interest, the results summarized in Table I also indicate a strong dependence of $\mathrm{Mg}$ incorporation on surface polarity for identical growth conditions. In particular, at higher $\mathrm{Mg}$ flux and growth temperatures, $\mathrm{Mg}$ incorporation is found to be approximately fifteen to twenty times less for N-polar GaN. A significant difference was observed for each set of comparable conditions examined, with larger incorporation always occurring for the Ga-polarity.

Lower Mg-incorporation rates for $\mathrm{N}$-polar material explains one of the puzzling results obtained for large $\mathrm{Mg}$-flux conditions associated with Ga-polarity growth. The presence of greater than a monolayer of $\mathrm{Mg}$ on the Ga-polarity GaN surface during growth results in the surface inverting to $\mathrm{N}$-polarity. ${ }^{13}$ SIMS measurement of $\mathrm{Mg}$ incorporation in a Ga-polarity step-doped sample indicated a dramatic decrease in $\mathrm{Mg}$ 
incorporation, from $\sim 10^{20}$ to $\sim 10^{18} \mathrm{~cm}^{-3}$, upon increasing the $\mathrm{Mg}$-oven temperature from 350 to $400{ }^{\circ} \mathrm{C}$. The latter oven temperature should result in a flux of approximately one monolayer/sec or greater of $\mathrm{Mg}$ arriving at the surface of the growing sample in our system. Subsequent transmission electron microscopy characterization indicated inversion from Ga- to N-polarity occurred when the growing layer was exposed to this large Mg flux. ${ }^{17}$ That is, the large $\mathrm{Mg}$ flux at the growing surface led to polarity inversion, which then resulted in a dramatic decrease in $\mathrm{Mg}$ incorporation since the sample was now N-polarity. Thus, the decrease in electrical activation reported previously $^{4,5}$ for a large Mg flux on Ga-polar material can be understood in terms of surface polarity inversion followed by reduced Mg incorporation. Additionally, this polarity-dependent incorporation is consistent with the lower electrical activation observed for N-polar growth compared to Ga-polar growth for the same growth conditions. ${ }^{6}$

The results shown in Fig. 1 and Table I also represent the first verification of the prediction $^{8}$ that the presence of hydrogen will enhance $\mathrm{Mg}$ incorporation. In particular, without hydrogen, no incorporation was observed for low Mg flux. The addition of atomic hydrogen caused incorporation at levels more consistent with projections from higher Mg-flux incorporation rates. The effect of hydrogen on maximum $\mathrm{Mg}$ incorporation was less pronounced at higher $\mathrm{Mg}$ flux or lower substrate temperature. Indeed, atomic hydrogen has little effect or may slightly lower the maximum incorporation at $650{ }^{\circ} \mathrm{C}$ for reasonable $\mathrm{Mg}$ flux. Although diffusion effects are also present in our samples, the presence of atomic hydrogen appeared to sharpen interfaces. However, the profiles still indicate that surface accumulation layers are forming, 
suggesting that the increase in sharpness is due to enhanced incorporation as opposed to the suppression of surface accumulation. Note also that while hydrogen generally enhances incorporation for both polarities, it does not eliminate the polarity dependence of $\mathrm{Mg}$ incorporation and in most cases accentuates this effect. SIMS on the Mg-doped layers grown with atomic hydrogen indicated that while hydrogen significantly increases $\mathrm{Mg}$ incorporation, hydrogen itself is not incorporated at significant levels. That is, if hydrogen is incorporated at the growing surface, it anneals out during growth at the temperatures used.

The concentration profiles of the Mg step-doped structures show the effects of both surface accumulation and diffusion during the long growth times used. Although complicated by the surface accumulation effects, analysis of the profiles yields an estimate for an upper limit of the Mg diffusion coefficient. For growth temperatures between 650 and $700{ }^{\circ} \mathrm{C}$, we estimate the $\mathrm{Mg}$ diffusion coefficient to be about $1 \times 10^{-15}$ $\mathrm{cm}^{2} / \mathrm{s}$, which is large enough that $\mathrm{Mg}$ diffusion may be of concern in the growth of multilayer structures, particularly at the higher temperatures used in MOCVD growth.

In conclusion, a dramatic difference for $\mathrm{Mg}$ incorporation rates was observed between the $\mathrm{N}$ - and Ga-polarity surfaces during Mg-doping of GaN by rf-plasma MBE. The decrease in electrical activation previously reported for higher Mg-flux conditions during doping of Ga-polar material can now be understood in terms of a combination of surface polarity inversion coupled with the lower incorporation rate for N-polarity GaN. Difficulties in Mg-doping of $\mathrm{N}$-polarity $\mathrm{GaN}$ can also be better understood in terms of the reduced incorporation rate. The presence of hydrogen was shown to enhance $\mathrm{Mg}$ 
incorporation rates for most growth conditions. Strong evidence for surface accumulation of Mg was also observed.

We acknowledge continuing useful conversations with R. M. Feenstra (Carnegie Mellon University) and W. A. Doolittle (Georgia Institute of Technology) on this topic. This work was supported at WVU by ONR Grant N00014-96-1-1008 and at WVU and Xerox-PARC by ONR Contract N00014-99-C-0161, both monitored by Colin E. C. Wood. 


\section{References}

1 W. Gotz, N.M. Johnson, J. Walker, D.P. Bour, and R.A. Street, Appl. Phys. Lett. 68, 667 (1996).

${ }^{2}$ H. Amano, M. Kito, K. Hiramatsu, and I. Akasaki, Jpn. J. Appl. Phys., Part 2 28, L2112 (1989).

3 S. Nakamura, T. Mukai, and M. Senoh, Jpn. J. Appl. Phys., Part 2 30, L1998 (1991).

4 I.P. Smorchkova, E. Haus, B. Heying, P. Kozodoy, P. Fini, J.P. Ibbetson, S. Keller, S.P. DenBaars, J.S. Speck, and U.K. Mishra, Appl. Phys. Lett. 76, 718 (2000).

5 M. A. L. Johnson, Zhonghai Yu, C. Boney, W. C. Hughes, J. W. Cook, Jr., J. F. Schetzina, H Zhao, B. J. Skromme, and J. A. Edmond, Mat, Res. Symp. Proc. 449, 215 (1997).

${ }^{6}$ L. K. Li, M. J. Jurkovic, W. I. Wang, J. M. Van Hove, and P. P. Chow, Appl. Phys. Lett. 76, 1740 (2000).

7 S. Guha, N. A. Bojarczuk and F. Cardone, Appl. Phys. Lett. 71, 1685 (1997).

8 J. Neugebauer and C. G. Van de Walle, Phys. Rev. Lett. 75, 4452 (1995).

9 T.H. Myers, L.S. Hirsch, L.T. Romano, and M.R. Richards-Babb, J. Vac. Sci. Technol. B16, 2261 (1998); Zhonghai Yu, S.L. Buczkowski, N.C. Giles, T.H. Myers and M.R. Richards-Babb, Appl. Phys. Lett. 69, 2731 (1996).

10 A.R. Smith, V. Ramachandra, R.M. Feenstra, D.W. Greve, A. Ptak, T. Myers, W. Sarney, L. Salamanca-Riba, M. Shin and M. Skowronski, MRS Internet J. Nitride Semicond. Res. 3, 12 (1998). 
11 E.J. Tarsa, B. Heying, X.H. Wu, P. Fini, S.P. DenBaars, and J.S. Speck, J. Appl. Phys. 82, 5472 (1997).

12 C. Bungaro, K. Rapcewicz, and J. Bernholc, Phys. Rev. B59, 9771 (1999).

13 V. Ramachandran, R. M. Feenstra, W. L. Sarney, L. Salamanca-Riba, J. E. Northrup, L. T. Romano and D. W. Greve, Appl. Phys. Lett. 75, 808 (1999).

14 J.W. Orton, C.T. Foxon, T.S. Cheng S.E. Hooper, S.V. Novikov, B. Ya. Ber and Yu. A. Kudriavtsev, J. Cryst. Growth 197, 7 (1999).

15 T.S. Cheng, S.V. Novikov, C.T. Foxon, and J.W. Orton, Solid State Comm. 109, 439 (1999).

16 V. Ramachandran, R. M. Feenstra, J. E. Northrup, and D. W. Greve, MRS Internet J. Nitride Semicond. Res. 5S1, W3.65 (2000).

17 L. T. Romano, J. E. Northrup, T. Myers and A. Ptak, Appl. Phys. Lett. 77, 2479 (2000). 
Table I. Mg concentrations, $[\mathrm{Mg}]$, for various growth and doping conditions. The surface polarity of each sample is indicated. The $[\mathrm{Mg}]$ dependence on polarity (the last two columns) is compared for similar growth conditions from layers grown in similar time periods. Comparison of $\mathrm{Mg}$-incorporation for growth with and without atomic $\mathrm{H}$ is also given.

\begin{tabular}{|c|c|c|c|c|c|c|c|}
\hline \multirow{2}{*}{$\mathrm{T}_{\text {sub }}$} & \multirow{2}{*}{$\mathrm{T}_{\mathrm{Mg}}$} & \multirow{2}{*}{$\begin{array}{l}\text { Surface } \\
\text { Polarity }\end{array}$} & \multirow{2}{*}[\mathrm{Mg}]{} & \multirow{2}{*}[\mathrm{Mg}]{$: \mathrm{H}$} & \multirow{2}{*}{$\begin{array}{c}{[\mathrm{Mg}] \text { Ratio }} \\
\text { with/ } \\
\text { without } \mathrm{H}\end{array}$} & \multicolumn{2}{|c|}{$\begin{array}{c}{[\mathrm{Mg}] \text { Ratio between }} \\
\mathrm{Ga} / \mathrm{N} \text { polarity }\end{array}$} \\
\hline & & & & & & $\begin{array}{c}\text { Without } \\
\mathrm{H}\end{array}$ & With $\mathrm{H}$ \\
\hline & & & & Film 9942 & & & \\
\hline 705 & 250 & $\mathrm{~N}$ & ND & ND & & & \\
\hline 705 & 300 & $\mathrm{~N}$ & $1.0 \times 10^{18}$ & $2.0 \times 10^{18}$ & 2.0 & & \\
\hline 705 & 350 & $\mathrm{~N}$ & $4.5 \times 10^{18}$ & $6.0 \times 10^{18}$ & 1.3 & & \\
\hline 705 & 400 & $\mathrm{~N}$ & $8.0 \times 10^{18}$ & $1.0 \times 10^{19}$ & 1.3 & & \\
\hline & & & & Film 9950 & & & \\
\hline 700 & 350 & $\mathrm{Ga}$ & $7.0 \times 10^{19}$ & $2.0 \times 10^{20}$ & 2.9 & $16^{(\mathrm{a}}$ & $33^{(\mathrm{a}}$ \\
\hline 725 & 350 & $\mathrm{Ga}$ & $9.0 \times 10^{18}$ & $2.3 \times 10^{19}$ & 2.6 & & \\
\hline & & & & Film 9973 & & & \\
\hline 650 & 250 & $\mathrm{~N}$ & ND & $8.1 \times 10^{16}$ & $>200$ & & \\
\hline 675 & 250 & $\mathrm{~N}$ & ND & $1.0 \times 10^{17}$ & $>250$ & & \\
\hline 650 & 300 & $\mathrm{~N}$ & $3.3 \times 10^{17}$ & $2.1 \times 10^{17}$ & 0.6 & & \\
\hline 675 & 300 & $\mathrm{~N}$ & $2.3 \times 10^{17}$ & $5.4 \times 10^{17}$ & 2.3 & & \\
\hline 700 & 300 & $\mathrm{~N}$ & $6.5 \times 10^{16}$ & $5.9 \times 10^{17}$ & 9.1 & & \\
\hline & & & & Film 9974 & & & \\
\hline 650 & 250 & $\mathrm{Ga}$ & ND & $3.3 \times 10^{17}$ & $>165$ & & $4.1^{(b}$ \\
\hline 675 & 250 & $\mathrm{Ga}$ & ND & $2.8 \times 10^{17}$ & $>140$ & & $2.8^{(b}$ \\
\hline 650 & 300 & $\mathrm{Ga}$ & $5.8 \times 10^{18}$ & $5.3 \times 10^{18}$ & 0.9 & $18^{(b}$ & $25^{(b}$ \\
\hline 675 & 300 & $\mathrm{Ga}$ & $1.1 \times 10^{18}$ & $1.5 \times 10^{18}$ & 1.4 & $4.8^{(b}$ & $2.8^{(b}$ \\
\hline 700 & 300 & $\mathrm{Ga}$ & $1.9 \times 10^{17}$ & $2.7 \times 10^{18}$ & 14 & $2.9^{(b}$ & $4.6^{(b}$ \\
\hline
\end{tabular}

ND: Not detected

(a Compares 9950/9942

${ }^{\text {(b }}$ Compares 9974/9973 


\section{Figure Captions}

Figure 1. Mg concentration in a Ga-polarity step-doped GaN layer for various substrate and $\mathrm{Mg}$-oven temperatures. $\mathrm{Mg}$ shutter opening and closing is shown schematically.

Figure 2. Mg concentration profiles for (a) N-polarity and (b) Ga-polarity exhibiting evidence of surface accumulation layers. Mg shutter opening and closing is shown schematically. Both were grown at a substrate temperature of $650{ }^{\circ} \mathrm{C}$ and a $\mathrm{Mg}$ source temperature of $300{ }^{\circ} \mathrm{C}$. Note the change in concentration scale, as significantly more $\mathrm{Mg}$ incorporated in the Ga-polarity layer. 


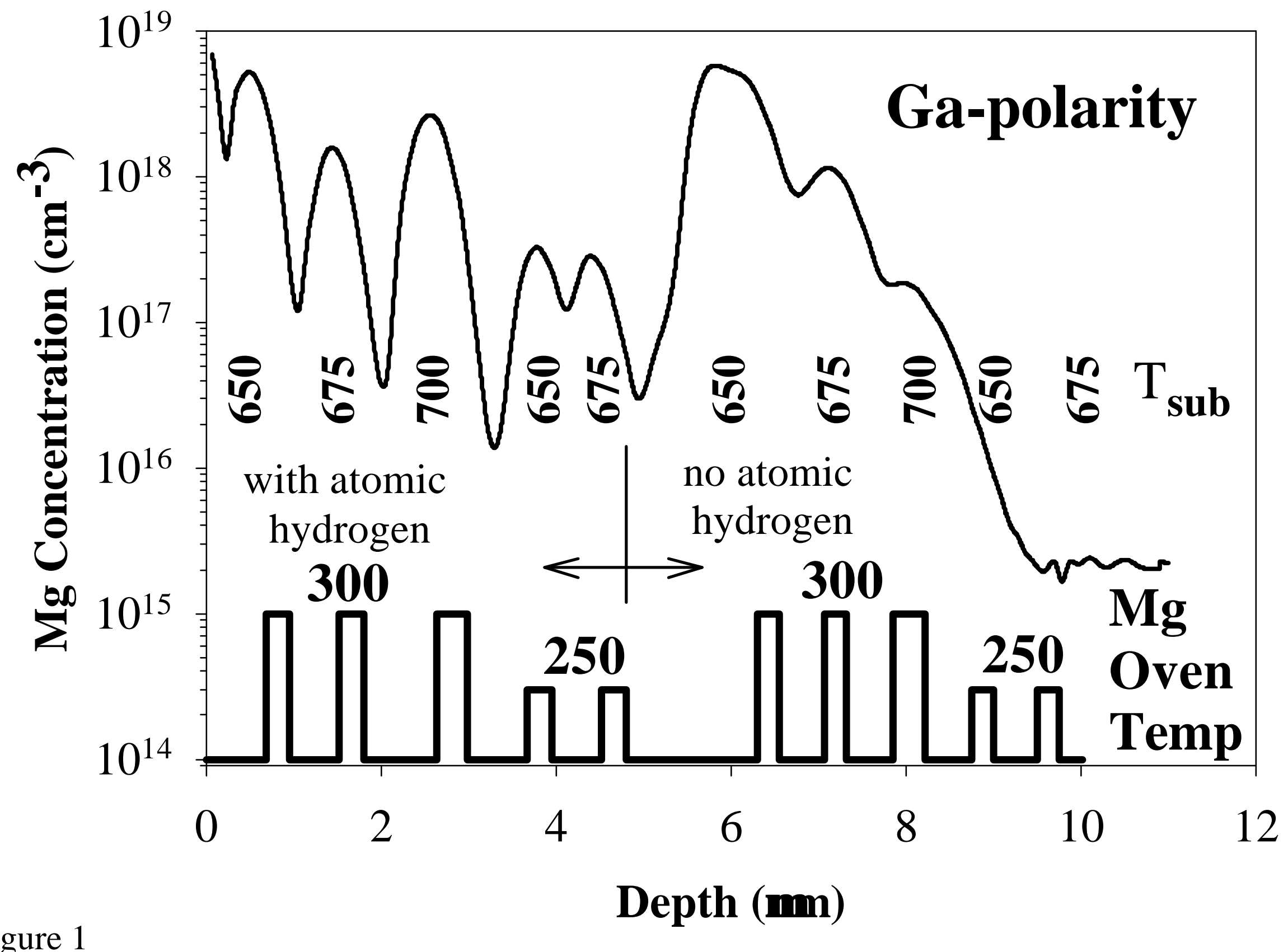



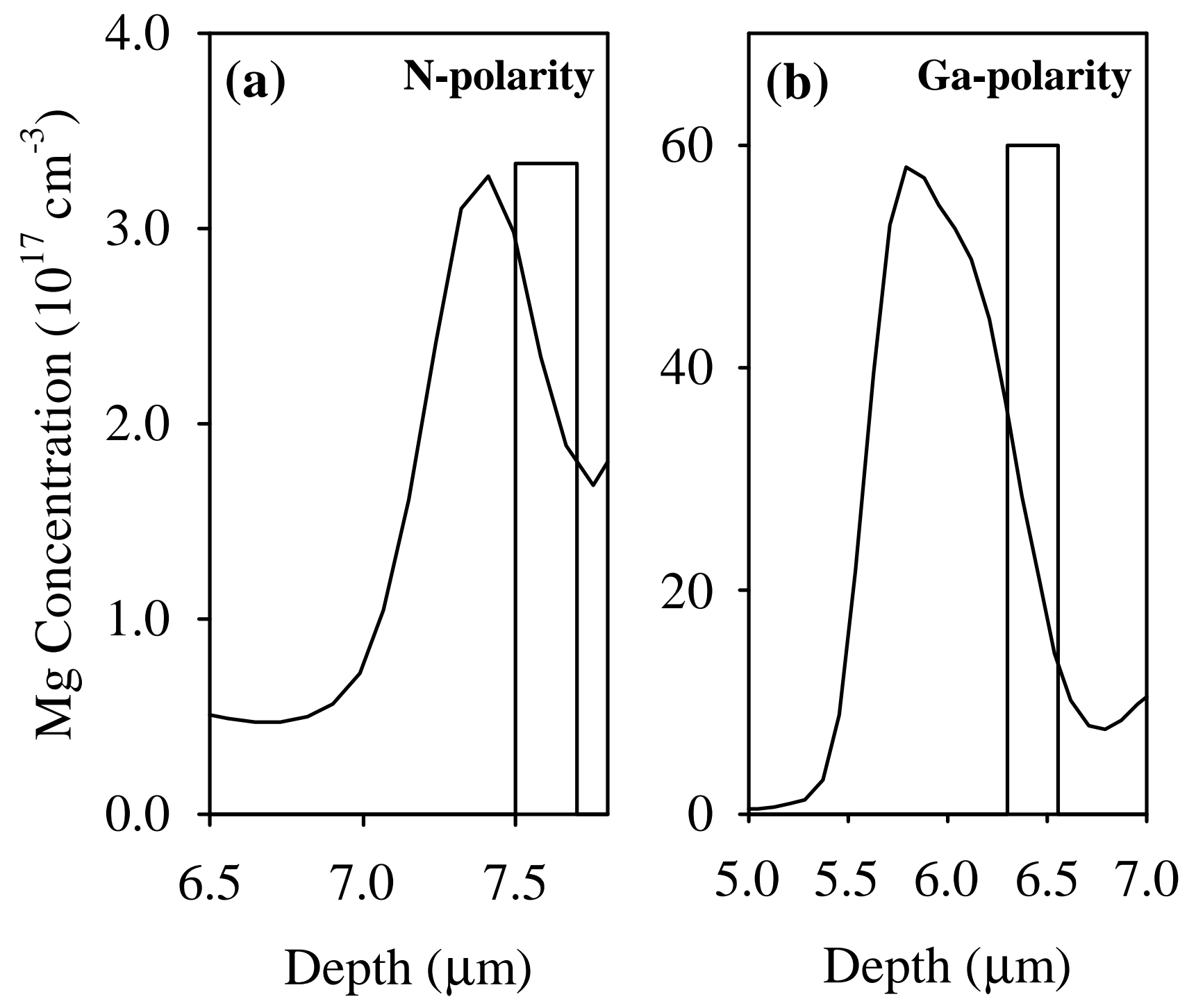

Figure 2 